\title{
Placental weight, birth measurements, and blood pressure at age 8 years
}

\author{
V M Moore, A G Miller, T J C Boulton, R A Cockington, I Hamilton Craig, \\ A M Magarey, J S Robinson
}

\begin{abstract}
Objective-To examine relationships between blood pressure during childhood and both placental weight and body size at birth, in an Australian population.

Design-A follow up study of a birth cohort, undertaken when cohort members were aged 8 years.

Setting-Adelaide, South Australia.

Subjects-830 children born in the Queen Victoria Hospital in Adelaide, South Australia, during 1975-6.

Main outcome measures-Systolic and diastolic blood pressure measured when the children were aged 8 years.

Results-Blood pressure at 8 years was positively related to placental weight and inversely related to birth weight, after adjusting for the child's current weight. For diastolic pressure there was a decrease of $1.0 \mathrm{~mm} \mathrm{Hg}$ for each $1 \mathrm{~kg}$ increase in birth weight $(95 \%$ confidence interval (CI) $=-0.4$ to 2.4) and an increase of 0.7 $\mathrm{mm} \mathrm{Hg}$ for each $100 \mathrm{~g}$ increase in placental weight $(95 \% \mathrm{CI}=0.1$ to 1.3$)$. Diastolic pressure was also inversely related to chest circumference at birth, independently of placental weight, with a decrease of $0.3 \mathrm{~mm} \mathrm{Hg}$ for each $1 \mathrm{~cm}$ increase in chest circumference $(95 \% \mathrm{CI}=0.2$ to 0.5$)$. Conclusions-These findings are further evidence that birth characteristics, indicative of fetal growth patterns, are related to blood pressure in later life. (Arch Dis Child 1996;74:538-541)
\end{abstract}

Keywords: birth weight, placental weight, blood pressure.

Department of

Community Medicine,

University of Adelaide,

South Australia

VM Moore

Queen Victoria

Hospital, Adelaide,

South Australia

AG Miller

JS Robinson

Adelaide Children's Hospital, Adelaide, South Australia

TJC Boulton

RA Cockington

I Hamilton Craig

AM Magarey

Correspondence to: Ms VM Moore, Department of Community Medicine,

University of Adelaide, South

Australia 5005, Australia.

Accepted 22 February 1996

Low birth weight has been related to raised blood pressure in later life in a number of study populations. The association was first shown in a British national cohort aged 36 years ${ }^{1}{ }^{2}$ and was subsequently reported for a group of Swedish army recruits. ${ }^{3}$ Three follow up studies of middle aged men and women who were born in three different parts of Britain have confirmed the finding and demonstrated that it is independent of current body size and lifestyle factors such as smoking habit and alcohol intake. ${ }^{4}{ }^{5}$ A number of studies of children have also provided evidence of this relationship. ${ }^{4} 6{ }^{6} 7$

In several studies an association between birth weight and later blood pressure has not been apparent, however. Findings among teenagers have been mixed, ${ }^{8-11}$ possibly due to the disruptive effects of rapid growth during adolescence on blood pressure patterns. ${ }^{12}$ No association was found among a group of children living in Britain, aged approximately 8 years, but they were all born before term and had low birth weights. ${ }^{13}$ In a small group of Jamaican children, blood pressure at 10 to 12 years was not related to birth weight, but was inversely related to the skinfold thickness of the mother during pregnancy. ${ }^{14}$ Likewise, among children of rural Gambia, an association between blood pressure and birth weight was absent but relationships with mother's weight during pregnancy were present. ${ }^{15}$ These latter results may point to more fundamental factors, such as maternal nutrition, which may underlie the relationship between birth weight and blood pressure seen elsewhere.

Birth weight is only a summary measure of growth in utero and further indications of intrauterine growth can be obtained from other features of the baby at birth, such as its length and fatness, and from the weight of the placenta. Relationships between blood pressure and placental weight have been examined in two recent studies. The first was a follow up study of individuals born between 1935 and 1944 in Preston, England, undertaken by Barker and colleagues. ${ }^{16}{ }^{17}$ Among 449 men and women aged around 50 years, raised blood pressure was associated with the combination of high placental weight and relatively low birth weight more strongly than it was to birth weight alone. Weaker evidence of the same pattern was found among 4 year old children from Salisbury, England. ${ }^{7}$ (In one other study concerning a group of children from Dunedin, New Zealand, findings were inconsistent. ${ }^{10}$ However, the series of comparison groups created and the comparisons reported do not enable assessment of the overall relationship in that sample.)
The studies in Preston and Salisbury also showed that blood pressure was related to body proportions at birth, with individuals who were characterised by relative thinness or shortness at birth having a greater likelihood of high blood pressure than those who were normally proportioned at birth. These relationships were independent of current body size and, remarkably, in the Preston group blood pressure was related to the body dimensions measured some 50 years earlier more strongly than it was to any current measurement.

We report a study of 830 children born at term in a hospital in Adelaide, South Australia, for whom details of body size and placental weight were recorded. Measurements of blood 
Table 1 Characteristics of the sample

\begin{tabular}{llc}
\hline Variable & No & Mean (SD) \\
\hline Birth weight (g) & 775 & $3392(534)$ \\
Placental weight (g) & 774 & $564(113)$ \\
Length at birth (cm) & 694 & $50.1(2.1)$ \\
Head circumference at birth (cm) & 694 & $34.6(1.5)$ \\
Chest circumference at birth (cm) & 694 & $33.9(2.0)$ \\
Weight at 8 years (kg) & 827 & $30.6(6.1)$ \\
Height at 8 years (cm) & 828 & $133.5(6.2)$ \\
Systolic blood pressure at 8 years (mm Hg) & 829 & $101.6(11.3)$ \\
Diastolic blood pressure at 8 years (mm Hg) & 825 & $61.2(8.7)$ \\
\hline
\end{tabular}

pressure were made when the children were aged 8 years and we analysed these in relation to placental weight and birth measurements.

\section{Subjects and methods}

A follow up study of children born at term during 1975-6 in the Queen Victoria Hospital, Adelaide, South Australia, was conducted when the children reached 8 years of age. Two thousand children had been sequentially selected at birth for measurement of cord serum lipids and these formed the group eligible for inclusion in the follow up study. Full details of the follow up procedures are given elsewhere. ${ }^{18}$ Briefly, around the time of their 8th birthday a total of 1347 children were able to be traced and were still living. After being contacted, the families of 856 of these children (64\%) agreed to participate in the follow up study. Almost half of the families that declined involvement did not live in the Adelaide metropolitan area. For the present analysis the 13 pairs of twins were excluded, leaving a total of 830 children.

The children attended the Adelaide Children's Hospital during 1984-5 for the follow up examination. Weight was measured to the nearest $100 \mathrm{~g}$ using beam balance scales, with the child lightly clothed but shoeless. Height was measured to the nearest $\mathrm{cm}$ using a Harpenden stadiometer. Blood pressure was measured in the right arm with the child lying down, using a standard mercury sphygmomanometer and a cuff size appropriate to the circumference of the arm. ${ }^{19}$ Diastolic pressure was read at the 4 th Korotkoff phase. Two measurements were made of both systolic and diastolic pressure, with a 10 minute interval between the readings.

Information relating to the births of the children was obtained from records held by the Queen Victoria Hospital. Details abstracted included birth weight, crown-heel length, head circumference, chest circumference, and placental weight. The placentas had been weighed untrimmed and without blood being expressed. Chest circumference was measured at the level of the nipples.

We used multiple linear regression and tabulation of group means to examine relationships between measurements made at birth and blood pressure at age 8 , as follows. The average of the two readings made of systolic and diastolic pressure, respectively, were used in the analyses. All measurements of placental weight and body size at birth, size at 8 years, and blood pressure were used as continuous variables in multiple regression. All relationships were investigated using multiple linear regression; partial regression coefficients and their 95\% confidence intervals (CIs) are reported. For clarity of presentation, we have shown the results as tables of mean values of blood pressure within groups. For each variable, the groups were formed on the basis of tertiles, so that approximately a third of the sample fell into each group.

\section{Results}

Among the 830 children studied, there were 437 boys and 393 girls. Characteristics of the sample at birth and at 8 years are presented in table 1 . Birth information was retrieved for 778 (94\%) of the children, although it was not complete in all cases. No records could be found for the remaining 52 children. Each part of the following analysis was carried out using those children who had valid data for all variables in that particular model.

The distribution of birth weight for the group of children studied (summarised in table 1 ) is very similar to that for all singleton babies born at term in South Australia during 1981 (mean (SD) 3387( 557) g), which was the first year for which statewide birth statistics were compiled; the statewide distribution of birth weight has been stable from 1981 to 1994 (A Chan, personal communication, 21 August 1995).

In the study sample, the mean (SD) systolic pressure for boys was 101(11) $\mathrm{mm} \mathrm{Hg}$ while that for girls was $102(12) \mathrm{mm} \mathrm{Hg}$. For both boys and girls, the mean (SD) diastolic pressure was $61(9) \mathrm{mm} \mathrm{Hg}$. Including the child's sex had no effect on any of the regression models, so we did not adjust for this variable.

Blood pressure was strongly related to current weight. Systolic pressure rose by 0.6 $\mathrm{mm} \mathrm{Hg}$ and diastolic pressure by $0.4 \mathrm{~mm} \mathrm{Hg}$ for each $1 \mathrm{~kg}$ increase in current weight. Relationships with height and body mass index were weaker and the addition of either variable to weight in a linear regression model did not explain a larger fraction of the variance in blood pressure. We therefore adjusted only for current weight in all subsequent analyses.

Birth weight alone was not related to blood pressure. Placental weight alone was not related to systolic pressure. There was a positive but not statistically significant relationship between placental weight and diastolic pressure.

The simultaneous effects of placental weight and birth weight on blood pressure were examined by multiple regression. At any birth weight, blood pressure tended to rise with increasing placental weight. At any placental weight, blood pressure tended to fall with increasing birth weight. Therefore, the highest blood pressures were found among those children who had the largest placentas and the lowest birth weights, and vice versa. For diastolic pressure, there was an increase of 0.7 $\mathrm{mm} \mathrm{Hg}$ for each $100 \mathrm{~g}$ increase in placental weight ( $95 \% \mathrm{CI}=0.1$ to 1.3 ) and a decrease of $1.0 \mathrm{~mm} \mathrm{Hg}$ for each $1 \mathrm{~kg}$ increase in birth weight $(95 \% \mathrm{CI}=-0.4$ to 2.4$)$. For systolic pressure the pattern was similar but not statis- 
Table 2 Mean systolic pressure $(\mathrm{mm} \mathrm{Hg})$ at age 8 years according to birth weight and placental weight groups, adjusted for current weight; numbers in each cell are shown in parentheses

\begin{tabular}{lllll}
\hline Birth weight $(g)$ & \multicolumn{5}{l}{ Placental weight $(g)$} & \\
\cline { 2 - 5 } & $\leqslant 500$ & $501-600$ & $>600$ & Total \\
\hline \multirow{3}{*}{3200} & $101.4(162)$ & $102.3(71)$ & $103.0(23)$ & 102.2 \\
$3201-3600$ & $100.8(75)$ & $101.7(107)$ & $102.4(63)$ & 101.6 \\
$>3600$ & $99.7(20)$ & $100.5(78)$ & $101.3(175)$ & 100.5 \\
Total & 100.6 & 101.5 & 102.2 & \\
\hline
\end{tabular}

Table 3 Mean diastolic pressure $(\mathrm{mm} \mathrm{Hg})$ at age 8 years according to birth weight and placental weight groups, adjusted for current weight; numbers in each cell are shown in parentheses

\begin{tabular}{lllll}
\hline Birth weight $(g)$ & \multicolumn{4}{l}{ Placental weight $(g)$} \\
\cline { 2 - 5 } & $\leqslant 500$ & $501-600$ & $>600$ & Total \\
\hline$\leqslant 3200$ & $60.9(162)$ & $61.5(71)$ & $63.1(23)$ & 61.8 \\
$3201-3600$ & $60.4(75)$ & $61.0(107)$ & $62.6(63)$ & 61.3 \\
$>3600$ & $59.0(20)$ & $59.6(78)$ & $61.2(175)$ & 59.9 \\
Total & 60.1 & 60.7 & 62.3 & \\
\hline
\end{tabular}

Table 4 Mean systolic pressure ( $\mathrm{mm} \mathrm{Hg}$ ) at age 8 years according to placental weight and head circumference groups, adjusted for current weight; numbers in each cell are shown in parentheses

\begin{tabular}{lllll}
\hline \multirow{2}{*}{$\begin{array}{l}\text { Head } \\
\text { circumference }(\mathrm{cm})\end{array}$} & \multicolumn{4}{l}{ Placental weight $(\mathrm{g})$} \\
\cline { 2 - 5 } & $\leqslant 500$ & $501-600$ & $>600$ & Total \\
\hline$\leqslant 33$ & $101.2(56)$ & $101.8(40)$ & $102.3(19)$ & 101.8 \\
$34-35$ & $101.0(128)$ & $101.6(134)$ & $102.1(102)$ & 101.6 \\
$\geqslant 36$ & $100.3(25)$ & $100.9(67)$ & $101.4(119)$ & 100.9 \\
Total & 100.9 & 101.4 & 102.0 & \\
\hline
\end{tabular}

Table 5 Mean diastolic pressure $(\mathrm{mm} \mathrm{Hg})$ at age 8 years according to placental weight and chest circumference groups, adjusted for current weight; numbers in each cell are shown in parentheses

\begin{tabular}{lllll}
\hline \multirow{2}{*}{$\begin{array}{l}\text { Chest } \\
\text { circumference }(\mathrm{cm})\end{array}$} & \multicolumn{3}{l}{ Placental weight $(\mathrm{g})$} & \\
\cline { 2 - 5 } & $\leqslant 500$ & $501-600$ & $>600$ & Total \\
\hline$\leqslant 33$ & $60.8(124)$ & $61.3(93)$ & $62.3(40)$ & 61.5 \\
34 & $60.4(58)$ & $60.8(86)$ & $61.9(72)$ & 61.0 \\
$\geqslant 35$ & $59.9(27)$ & $60.3(62)$ & $61.4(128)$ & 60.5 \\
Total & 60.3 & 60.8 & 61.9 & \\
\hline
\end{tabular}

tically significant: an increase of $0.3 \mathrm{~mm} \mathrm{Hg}$ for each $100 \mathrm{~g}$ increase in placental weight $(95 \%$ $\mathrm{CI}=-0.5$ to 1.1 ) and a decrease of $1.3 \mathrm{~mm} \mathrm{Hg}$ for each $1 \mathrm{~kg}$ increase in birth weight $(95 \% \mathrm{CI}$ $=-0.5$ to 3.1 ). Tables 2 and 3 illustrate these results by presenting the mean systolic and diastolic pressures for children grouped according to approximate thirds of placental weight and birth weight.

We investigated relationships between blood pressure and other birth measurements in combination with placental weight. The birth measurements considered were head circumference, chest circumference, crown-heel length, the ratio of head circumference to length, and ponderal index (the ratio of birth weight to length cubed). For systolic pressure, the strongest relationship was with head circumference, with a decrease of $0.5 \mathrm{~mm} \mathrm{Hg}$ for each $1 \mathrm{~cm}$ increase in head circumference (95\% CI $=-0.1$ to 1.1$)$. This pattern of results is illustrated in table 4 , which gives mean systolic pressure for children grouped according to approximate thirds of placental weight and head circumference. There was no evidence of any other patterns of association.

Diastolic pressure was associated with chest circumference independently of placental weight. At any placental weight, blood pressure tended to fall with increasing chest circumference, with a decrease of $0.3 \mathrm{~mm} \mathrm{Hg}$ for each one $\mathrm{cm}$ increase in chest circumference $(95 \%$ $\mathrm{CI}=0.2$ to 0.5 ). At any chest circumference, blood pressure tended to rise with increasing placental weight, with an increase of $0.7 \mathrm{~mm}$ $\mathrm{Hg}$ per $100 \mathrm{~g}$ increase in placental weight ( $95 \% \mathrm{CI}=0.1$ to 1.3 ). This pattern of results is illustrated in table 5 , which gives mean diastolic pressure for children grouped according to approximate thirds of placental weight and chest circumference. There was no evidence of any other patterns of association.

\section{Discussion}

In a group of 8 year old Australian children, born at term, we found that systolic and diastolic blood pressures were related to placental weight and size at birth. The children were selected only through having been born in a particular hospital during a certain period of time (1975-6). The birth weight distribution of the children studied was very similar to the corresponding statewide distribution for the nearest year for which statewide data were available (1981). Over the period for which it has been documented (1981-94), the statewide birth weight distribution has remained stable. Thus the group of children who participated in the follow up study appear to be a representative sample in terms of birth weight. Moreover, our analyses are based on withinsample comparisons. The results will therefore not be subject to bias unless the relationships between blood pressure and measurements made at birth are systematically different for children not included in the study, which seems unlikely.

That blood pressure is inversely related to birth weight and, simultaneously, positively associated with placental weight has been demonstrated in two studies in Britain. ${ }^{7}{ }^{16} \mathrm{As}$ in those studies, we found that the highest blood pressures were observed among individuals who had a large placenta in relation to their birth weight. Barker and his colleagues have speculated that maternal nutrition underlies this relationship. ${ }^{20}$ Support for this view comes from recent work in experimental animals. In previously well fed sheep, moderate undernutrition in mid-pregnancy has been found to stimulate placental growth. ${ }^{21}{ }^{22}$ In late pregnancy, a brief period of undernutrition has been related to increased fetal blood pressure after the mother's diet was restored to normal. ${ }^{23}$ In rats, reduced intake of protein has been shown to promote placental growth and constrain fetal growth. ${ }^{24}$ Follow up of pups showed that all offspring from mothers on diets comprising $6-12 \%$ protein had significantly raised blood pressure. ${ }^{25}$ Thus the initiating event in hypertension can occur prenatally. ${ }^{12}{ }_{26}$

Raised blood pressure has repeatedly been shown to be related to smallness at birth, although this finding is not universal. In our 
data the relationship with birth weight emerged only after adjustment for placental weight. Previous studies that did not find associations between birth weight and blood pressure did not take placental weight into account.

Birth weight is a summary measure of fetal growth and does not distinguish differences in head size, length, or fatness. Barker and his colleagues have shown that two other phenotypic groups of babies, not necessarily of low birth weight, are prone to develop raised blood pressure. ${ }^{7}{ }^{16}$ One group comprises babies that are disproportionately thin and the other, babies that are disproportionately short. These birth phenotypes are thought to reflect different patterns of impaired growth in utero. ${ }^{20}$ In our study, raised diastolic pressure was associated with small chest circumference and this result again implicates thinness at birth in subsequent increase of blood pressure.

At present, the mechanisms underlying the relationship between retarded fetal growth and raised blood pressure are not clear, and their elucidation requires further work in animals and humans. It has been suggested that the relationship between blood pressure and fetal growth is progressively amplified throughout life. ${ }^{4}$ We plan to revisit the members of our study group, who are now approaching 20 years of age, and take further blood pressure measurements to test this.

We are grateful to the parents and children who participated in this study. We thank Alistair Woodward, Philip Ryan, and Julie Owens for helpful discussions regarding the study and drafts of the manuscript. The study was funded in part by the National Health and Medical Research Council of Australia and the Channel 10 Children's Medical Research Foundation of South Australia.

1 Wadsworth MEJ, Cripps HA, Midwinter RE, Colley JRT Blood pressure in a national birth cohort at the age of 36 related to social and familial factors, smoking, and body mass. BMF 1985; 291: 1534-8.

2 Barker DJP, Osmond C, Golding J, Kuh D, Wadsworth MEJ. Growth in utero, blood pressure in childhood and adult life, and mortality from cardiovascular disease. $B M F$ 1989; 298: 564-7.

3 Gennser G, Rymark P, Isberg PE. Low birth weight and risk of high blood pressure in adulthood. BMF 1988; 296: 1498-500.

4 Law CM, de Swiet M, Osmond C, et al. Initiation of hypertension in utero and its amplification throughout life. $B M \mathcal{F}$ 1993; 306: 24-7.
5 Martyn CN, Barker DJP, Jespersen S, Greenwald S, Osmond C, Berry C. Growth in utero, adult blood pressure, and arterial compliance. Br Heart $\mathcal{F}$ 1995; 73: 116-21.

6 Whincup PH, Cook DG, Shaper AG. Early influences on blood pressure: a study of children aged 5-7 years. $B M \mathcal{F}$ 1989; 299: 587-91.

7 Law CM, Barker DJP, Bull AR, Osmond C. Maternal and fetal influences on blood pressure. Arch Dis Child 1991; 66: 1291-5.

8 Seidman DS, Laor A, Gale R, Stevenson DK, Mashiach S Danon YL. Birth weight, current body weight, and blood pressure in late adolescence. $B M \mathcal{F} 1991$; 302: 1235-7.

9 Macintyre S, Watt G, West P, Ecob R. Correlates of blood pressure in 15 year olds in the west of Scotland. $\mathcal{F}$ Epidemiol Community Health 1991; 45: 143-7.

10 Williams S, St George IM, Silva PA. Intrauterine growth retardation and blood pressure at age seven and eighteen f Clin Epidemiol 1992; 45:1257-63.

11 Matthes JWA, Lewis PA, Davies DP, Bethel JA. Relation between birth weight at term and systolic blood pressure in adolescence. BM Y 1994; 308: 1074-7.

12 Lever AF, Harrap SB. Essential hypertension: a disorder of growth with origins in childhood? $\mathcal{f}$ Hypertens 1992; 10: growth

13 Lucas A, Morley R. Does early nutrition in infants born before term programme later blood pressure? $B M \Im$ 1994 309: 304-8.

14 Godfrey KM, Forrester T, Barker DJP, et al. Maternal nutritional status in pregnancy and blood pressure in childhood. Br f Obstet Gynaecol 1994; 101: 398-403.

15 Margetts BM, Rowland MGM, Foord FA, Cruddas AM Cole TJ, Barker DJP. The relation of maternal weight to the blood pressure of Gambian children. Int $\mathcal{F}$ Epidemiol 1991; 20: 938-43.

16 Barker DJP, Bull AR, Osmond C, Simmonds SJ. Fetal and placental size and risk of hypertension in adult life. $B M F$ 1990; 301: 259-62.

17 Barker DJP, Godfrey KM, Osmond C, Bull A. The relation of fetal length, ponderal index and head circumference to of fetal length, ponderal index and head circumference to Paediatr Perinat Epidemiol 1992; 6: 35-44.

18 Boulton TJC, Cockington RA, Craig IH, Magarey AM, Mazumdar J. A profile of heart disease risk factors and their relation to parents' education, fathers' occupation and history of heart disease in 844 South Australian families: the Adelaide Children's WHO Collaborative Study. $f$ Paediatr Child Health 1995; 31: 200-6.

19 Long M, Dunlop JR, Holland WW. Blood pressure recording in children. Arch Dis Child 1971; 46: 636-40.

20 Barker DJP, Gluckman PD, Godfrey KM, Harding JE, Owens JA, Robinson JS. Fetal nutrition and cardiovascular disease in adult life. Lancet 1993; 341: 938-41.

21 McCrabb GJ, Egan AR, Hosking BJ. Maternal undernutrition during mid-pregnancy in sheep: variable effects on tion during mid-pregnancy in sheep: variable effects on placental

22 DeBarro TM, Owens JA, Earl CR, Robinson JS. Nutrition during early/mid pregnancy interacts with mating weight to affect placental weight in sheep. Proceedings of the Australian Society of Reproductive Biology 1992; 35: 70

23 Harding JE, Johnston BM. Nutrition and fetal growth Reprod Fertil Dev (in press).

24 Levy L, Jackson AA. Modest restriction of dietary protein in the rat: fetal and placental growth. $\mathcal{F}$ Dev Physiol 1993; 19 113-8.

25 Langley SC, Jackson AA. Increased systolic blood pressure in adult rats induced by fetal exposure to maternal low protein diets. Clin Sci 1994; 86:217-22.

26 Folkow B. Cardiovascular structural adaptation: its role in the initiation and maintenance of primary hypertension. Clin Sci Mol Med 1978; 55: 3-22s. 